\title{
Protective Effect of Virgin Coconut Oil on Cyclophosphamide-induced Histological Changes in Lymphoid Tissues
}

Mu'izuddin M. Senin ${ }^{1}$, Imad M. Al-Ani ${ }^{1 *}$, Mohamed Imad A. M. Mahmud ${ }^{1}$, Naznin Muhammad ${ }^{2}$, Hanif M. Kasmuri ${ }^{2}$

\author{
${ }^{1}$ Department of Basic Medical Sciences, Kulliyyah of Medicine, International Islamic University Malaysia, \\ Kuantan, 25200, Malaysia \\ ${ }^{2}$ Department of Pathology, Kulliyyah of Medicine, International Islamic University Malaysia, Kuantan, \\ 25200, Malaysia
}

\section{ABSTRACT}

Introduction: Virgin coconut oil (VCO) is known for its health and therapeutic benefits. However, the immunomodulatory effects of VCO have not been extensively investigated. Objective: The present study was devoted to examining the effects of VCO on cyclophosphamide (CY)-induced toxicity of lymphoid tissues. Methods: Thirty healthy male Wistar rats were sorted into 5 groups of 6 animals. The first control (NC) group was given distilled water via gavage at $5 \mathrm{ml} / \mathrm{kg}$ once daily. The second (CY) group received $\mathrm{CY}$ orally at $10 \mathrm{mg} / \mathrm{kg} /$ day for 4 weeks. Rats in the other three groups (CV5, CV10, and CV15) were given 10 $\mathrm{mg} / \mathrm{kg} /$ day CY for 4 weeks, $5 \mathrm{~m} / \mathrm{kg} /$ day, $10 \mathrm{ml} / \mathrm{kg} /$ day and $15 \mathrm{ml} / \mathrm{kg} /$ day VCO for 6 weeks, respectively. Rats were sacrificed at the end of $6^{\text {th }}$ week; blood sample from the animals was collected for full blood count and biochemical analysis. The thymus and spleen of each animal was processed for histological examination. Results: The thymus and spleen showed marked reduction in lymphoid cellularity following daily administration of $\mathrm{CY}$. The thymus also showed a marked reduction in the size of the medulla, and the white pulp areas of spleen had reduction in the follicle number and size. Supplementation with $10 \mathrm{ml} / \mathrm{kg}$ and $15 \mathrm{ml} / \mathrm{kg}$ VCO showed evidence of restoration of both the thymus and splenic lymphoid architecture. The total white cell counts, absolute lymphocyte counts and plasma globulin levels of the VCO groups were significantly increased compared to CY group. Conclusion: VCO displayed potential protective effects on CYinduced histological changes in lymphoid tissues.

KEYWORDS: Cyclophosphamide, Immunomodulatory, Spleen, Thymus, Virgin Coconut Oil.

\section{INTRODUCTION}

The use of cyclophosphamide (CY) and other cytotoxic chemotherapeutic agents is associated with immunotoxicity that would increase the risk of immunosuppression-related complications in patients treated with these drugs. ${ }^{1,2}$ The occurrence of these side effects cause reduced quality of life and treatment compliance. ${ }^{3}$ Modulation of immune functions using medicinal

Corresponding author:

Assoc. Prof. Dr. Imad Matloub Al-Ani

Department of Basic Medical Sciences,

Kulliyyah of Medicine,

International Islamic University Malaysia

Tel : 609-5704000

Email: imadmatloub@iium.edu.my plants and their products has become an accepted therapeutic approach. ${ }^{4}$ As a result, several plant extracts and their immunomodulatory properties are being researched for potential benefits in lessening or overcoming these adverse effects of cancer chemotherapy. ${ }^{5}$

The increasing popularity of VCO has led to new research in its clinical application apart from its role as functional food oil; it has been shown that the coconut oil is effective in reducing oral microbial load and decreasing plaque and gingival indices. ${ }^{6}$ VCO has been shown to possess antihypertensive, antimicrobial and anti-inflammatory properties. ${ }^{7,8}$ Additionally, VCO has been established clinically to be a potent moisturizer for patients with atopic dermatitis due to the anti-inflammatory and anti- 
infective activity as well as protector of the skin barrier. ${ }^{9}$ Clinical studies also revealed that VCO improves the symptoms of skin disorders by soothing the skin, decreased cutaneous inflammation and increased the epidermal barrier function and hydration property by decreasing transepidermal water loss in atopic dermatitis condition. ${ }^{10}$

Currently, clinical trials are being conducted on cardiovascular protective, breast cancer quality of life supplementation and other therapeutic and health beneficial effects of virgin coconut oil (VCO) and other plant-derived antioxidants. ${ }^{11-13}$ VCO is composed of about $92 \%$ saturated fats consisting of high level of medium-chain fatty acids i.e. lauric, caproic and caprylic acids. ${ }^{14}$ It also contains noticeable amounts of vitamins and polyphenols; the key players for antioxidant and anticarcinogenic properties. ${ }^{15}$ The medium-chain fatty acid content has been linked to a reduction in the risks of atherosclerosis and its complications. ${ }^{16,17}$ VCO also possessed free radical reducing and scavenging properties that correlated positively with the content of polyphenols in VCO. ${ }^{15}$

However, the immunomodulatory property of VCO has yet to be extensively explored. Therefore, the present study was conducted to investigate the protective effects of VCO on the CY-induced immunotoxicity in the experimental rat model. In this setting, the probable immune-protection induced by VCO, is sought after by observation for the clinical signs of toxicity, studying the hematological and biochemical profiles and the histopathological changes in the lymphoid tissues of experimental rats treated with different volumes doses of VCO used to test for the dose response effect.

\section{MATERIALS AND METHODS}

\section{Virgin coconut oil}

VCO was purchased from the Malaysian Agricultural Research and Development Institute (MARDI) (Serdang, Selangor, Malaysia). It was produced through a cold pressed method using MARDI's technology. ${ }^{18}$ In brief, the coconut white meat was grated and mixed with a certain amount of high quality water. The soaked grated meat was then mechanically pressed to produce coconut milk. The coconut milk was placed in a sterile container and left for 24 hours at room temperature following which the oil layer that partitions on top was scooped out and subjected to centrifugation. This step allows for sedimentation of fine particles and clarification of the oil.

\section{Animals}

Thirty adult male Wistar rats (age: 5-6 weeks) weighing approximately 100 - 200 gram were used. Each cage housed two rats under standard experimental conditions of $25^{\circ} \mathrm{C}$ with 12 hour-light and 12 hour-dark cycle each day. The rats were fed with rat chow (Gold Coin Sdn. Bhd., Malaysia) and distilled water given ad libitum. The study protocol was approved by the Institutional Animal Care and Use Committee (IACUC), International Islamic University Malaysia (IIUM). The experiment was conducted according to the Guidelines for the Care and Use of Laboratory Animals of the Kulliyyah of Medicine, IIUM.

\section{Experimental design}

The rats were divided into five groups of six animals each as described in Table 1. Cyclophosphamide (Merck Sdn. Bhd) at a dose of $10 \mathrm{mg} / \mathrm{kg} /$ day was given for 4 weeks while the VCO was given at different doses, namely $5 \mathrm{ml} / \mathrm{kg} /$ day, $10 \mathrm{ml} / \mathrm{kg} /$ day and $15 \mathrm{ml} / \mathrm{kg} /$ day for 6 weeks respectively. At the end of the treatment period, blood specimen from each animal was collected for hematological and biochemical analyses. All the rats were subsequently sacrificed and thymus and spleen were removed and fixed in $10 \%$ formalin saline for 72 hours at room temperature prior to processing, followed by haematoxylin and eosin (H\&E) staining.

Table 1: Distribution of animals by experimental groups

\begin{tabular}{|c|c|c|}
\hline Group & Definition & Treatment \\
\hline NC & $\begin{array}{l}\text { Normal control } \\
\text { rats }\end{array}$ & $\begin{array}{l}\text { Rat pellets and } \\
\text { water only } \\
\text { Rat pellets. }\end{array}$ \\
\hline $\mathrm{CY}$ & Cyclophosphamide & $\begin{array}{l}\text { water \& CY } 10 \\
\mathrm{mg} / \mathrm{kg} / \mathrm{day} \\
\mathrm{CY} 10 \mathrm{mg} / \mathrm{kg} /\end{array}$ \\
\hline CV5 & $\begin{array}{l}\text { Cyclophosphamide } \\
\text { \& VCO } 5\end{array}$ & $\begin{array}{l}\text { day \& VCO } 5 \\
\mathrm{~mL} / \mathrm{kg} / \mathrm{day}+ \\
\text { pellets and } \\
\text { water } \\
\text { CY } 10 \mathrm{mg} / \mathrm{kg} /\end{array}$ \\
\hline CV10 & $\begin{array}{l}\text { Cyclophosphamide } \\
\text { \& VCO } 10\end{array}$ & $\begin{array}{l}\text { day \& VČO } 10 \\
\mathrm{~mL} / \mathrm{kg} / \mathrm{day}+ \\
\text { pellets and } \\
\text { water }\end{array}$ \\
\hline CV15 & $\begin{array}{l}\text { Cyclophosphamide } \\
\text { \& VCO } 15\end{array}$ & $\begin{array}{l}\text { CY } 10 \mathrm{mg} / \mathrm{kg} / \\
\text { day \& VCO } 15 \\
\mathrm{~mL} / \mathrm{kg} / \mathrm{day}+ \\
\text { pellets and } \\
\text { water }\end{array}$ \\
\hline
\end{tabular}




\section{Hematological and biochemical analysis}

Blood specimens were analyzed for full blood count using the Advia 120 Hematology System. The serum obtained was analyzed for total protein, albumin, globulin, alanine aminotransferase, urea and creatinine levels (Thermo scientific Biochemical Analyzer).

\section{Statistical analysis}

Statistical analysis was performed using analysis of variance (ANOVA) available in the statistical programme SPSS version 20.0 to compare the hematological and biochemical parameters of the study groups. A value of $\mathrm{p}<0.05$ was considered to be significant.

\section{RESULTS}

\section{Histological changes in the thymus glands}

The control rats (NC group) showed normal histology of the thymus (Fig. 1a). Sections of the thymus of rats receiving only $\mathrm{CY}$ (CY group) showed depletion of lymphoid cell population in the medulla and cortex, shrinkage of the medulla, congestion of blood vessels, thickening of the capsule and trabeculae and increased number of macrophages (Fig. 1b). Rats in the group that received VCO at $5 \mathrm{ml} / \mathrm{kg} /$ day (CV5 group) exhibited similar changes in the thymus as those in group $\mathrm{CY}$ (Fig. 1c). Animals that were given VCO at $10 \mathrm{ml} / \mathrm{kg} /$ day (CV10 group) showed an increase in thymic cellularity and improvement in the shrinkage of the medulla as compared to group CY (Fig. 1d).

The increase in lymphoid cellularity in the cortex and medulla was more apparent as compared to CV5 group with few macrophages were seen in the cortex. Thymus of rats receiving the highest dose of VCO (CV15 group) showed a similar thymic architecture to the control group; the medullary size was almost similar to that of group NC with significant restoration of lymphoid cellularity both in the medulla and cortex (Fig. 1e).

\section{Histological changes in the spleen}

The spleen of the control group showed the normal architecture (Fig. 2a). Splenic sections of $\mathrm{CY}$ group rats showed that the white pulp had an overall reduction in lymphoid cellularity, particularly in the follicles and the marginal zone with the size and number of follicles being markedly diminished, the germinal centers were barely seen. In the splenic red pulp, there was marked depletion of lymphocytes with congestion of venous sinuses (Fig. 2b). As for rats in the group that received VCO at $5 \mathrm{ml} / \mathrm{kg} /$ day (CV5 group), the splenic sections also revealed marked depletion of lymphocytes in the follicles and marginal zones (Fig. 2c).

The red pulp showed congestion of sinusoids although it was less marked than in the $\mathrm{CY}$ group. On the other hand the histological features of the splenic section of $\mathrm{CV} 10$ group rats showed a marked increase in the cellularity of the white pulp as compared to CY and CV5 groups. The size of the follicles of the white pulp was also increased (Fig. 2d). There was evidence of germinal center regeneration as indicated by the presence of mitotic figures and follicular dendritic cells in the white pulp. The cellularity of the red pulp was also increased. Animals in the group that received VCO at $15 \mathrm{ml} / \mathrm{kg} /$ day (CV15 group) exhibited restoration of lymphocytes in the white pulp and the marginal zone. The cellularity of the red pulp was also increased with less marked sinusoid congestion (Fig. 2e).

\section{Full blood count and biochemical analysis}

Results of full blood count are shown in Table 2. Both the total white cell count (TWCC) and the absolute lymphocyte count showed increasing trends in the groups receiving VCO. Groups CV10 and CV15 had significantly higher TWCC and lymphocyte count as compared to group CY. However, the values did not quite approach the normal control levels. The results of the biochemical parameters are shown in Table 3. All groups administered VCO had significantly higher globulin levels than group CY. 


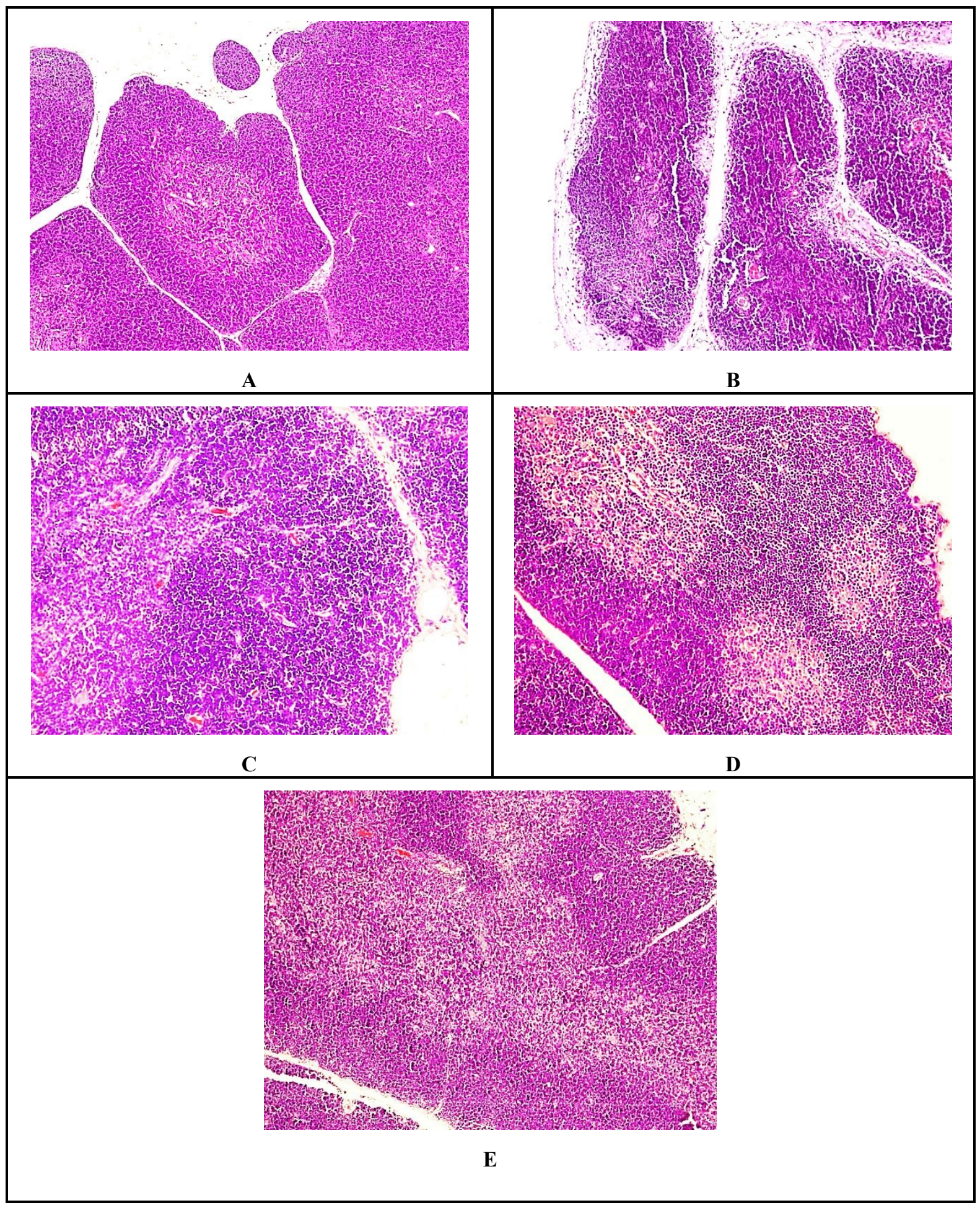

Figure 1. Haematoxylin and eosin stained sections of thymus. A. Normal thymic architecture of control group, $x$ 100. B. A thymic section from a rat in group CY showed thickening of the capsule and cortex, congested blood vessels, decreased lymphoid cells population in the medulla, $x$ 100. C. A thymic section of group CV5 rat showed no improvement in the thymus, $x$ 200. D. Histologic section of thymus from group CV10 rat showed restoration of lymphocytes in the thymus, normal size of the medulla, cortex and capsule, x 100. $\mathrm{E}$. Thymic section of rat from group CV15 showed normal thymic capsule, restoration of lymphocytes in the medulla and its size, $\times 100$. 


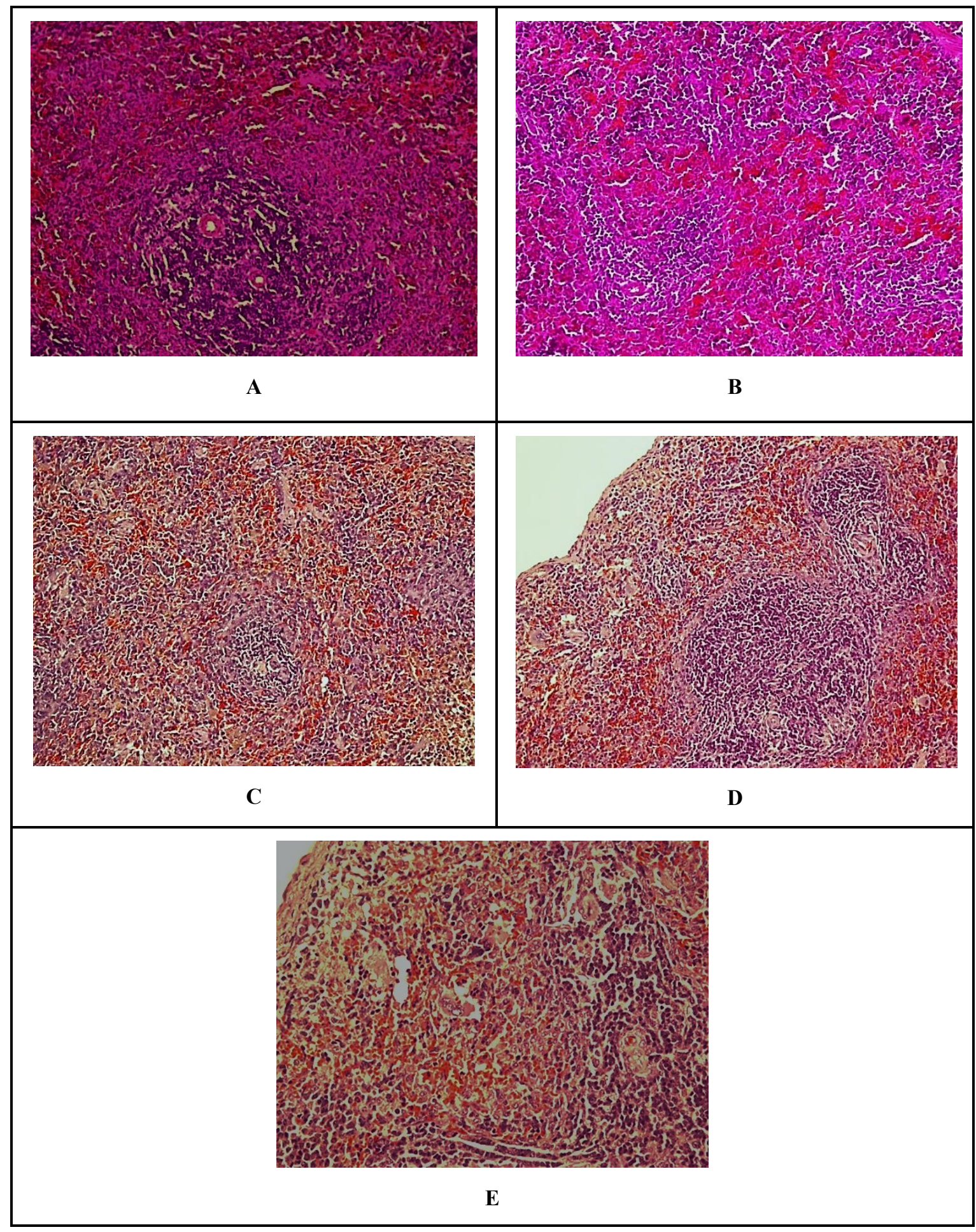

Figure 2. Haematoxylin and eosin stained sections of spleen. A. Group NC; Normal splenic architecture, $x$ 200. B. Group CY; Reduced diameter of the splenic follicles, congested BV's, thickening of the central artery, hyalinization, splenic lymphocyte depletion, and degenerated cytoplasm was observed in the germinal center, x 200. C. Group CV5; Depletion of lymphocytes in the white pulp, thickening of the central artery and hyalinization in the marginal zone was observed. The red pulp contained focal hemorrhagic areas while the trabeculae appeared less thickened as compared to the CY group, x 200 . D. Group CV10; Normal splenic capsule, restoration of lymphocytes in the white pulp, the marginal zone and the red pulp contain focal haemorrhagic areas, x 200. E. Group CV15; Restoration of lymphocytes in the white pulp and the marginal zone. The cellularity of the red pulp was also increased with less marked sinusoid congestion, $\mathrm{x} 200$. 
Table 2. Full blood count parameters of the different experimental animal groups.

\begin{tabular}{lllllll}
\hline Group & $\begin{array}{l}\text { TWCC } \\
\left(\times 10^{9} / \mathrm{L}\right)\end{array}$ & $\begin{array}{l}\text { Lymphocytes } \\
\left(\times 10^{9} / \mathrm{L}\right)\end{array}$ & $\begin{array}{l}\text { Neutrophils } \\
\left(\mathrm{x} 10^{9} / \mathrm{L}\right)\end{array}$ & $\begin{array}{l}\mathrm{RBCC} \\
\left(\mathrm{x} 10^{12} / \mathrm{L}\right)\end{array}$ & $\begin{array}{l}\text { Haemoglobin } \\
(\mathrm{g} / \mathrm{L})\end{array}$ & Platelets $\left(\mathrm{x} 10^{9} / \mathrm{L}\right)$ \\
\hline $\mathrm{NC}$ & $10.62 \pm 1.24$ & $6.82 \pm 2.13$ & $3.33 \pm 1.81$ & $8.56 \pm 0.44$ & $164.7 \pm 2.73$ & $747.33 \pm 195$ \\
$\mathrm{CY}$ & $3.32 \pm 1.87^{*}$ & $0.83 \pm 0.29^{*}$ & $2.28 \pm 1.85$ & $7.82 \pm 0.29$ & $151.3 \pm 4.90$ & $780.00 \pm 124$ \\
CV5 & $4.98 \pm 1.79^{*}$ & $1.97 \pm 0.55^{*}$ & $2.33 \pm 1.08$ & $7.74 \pm 0.18^{*}$ & $155.0 \pm 5.60$ & $598.16 \pm 78$ \\
CV10 & $7.88 \pm 2.60 \#$ & $3.35 \pm 1.26^{*} \#$ & $3.65 \pm 1.36$ & $8.27 \pm 0.29$ & $160.0 \pm 6.50$ & $925.33 \pm 256$ \\
CV15 & $8.22 \pm 2.32 \#$ & $3.95 \pm 0.78^{*} \#$ & $3.18 \pm 1.37$ & $7.32 \pm 0.82^{*}$ & $149.2 \pm 15.2$ & $790.67 \pm 298$ \\
\hline
\end{tabular}

Data presented as mean \pm SD $(n=6)$. $\mathrm{P}<0.05$ is considered significant (one-way ANOVA followed by post-Hoc test Tukey HSD);

${ }^{*} \mathrm{p}<0.05$ compared to Group NC

$\# \mathrm{p}<0.05$ compared to Group $\mathrm{CY}$

TWCC - Total white cell count

RBCC - Red blood cell count

Table 3. Biochemical parameters of the different experimental animal groups.

\begin{tabular}{lllllll}
\hline Group & $\begin{array}{l}\text { Total } \\
\text { protein } \\
(\mathrm{g} / \mathrm{L})\end{array}$ & $\begin{array}{l}\text { Albumin } \\
(\mathrm{g} / \mathrm{L})\end{array}$ & $\begin{array}{l}\text { Globulin } \\
(\mathrm{g} / \mathrm{L})\end{array}$ & ALT $(\mathrm{U} / \mathrm{L})$ & $\begin{array}{l}\text { Urea } \\
(\mathrm{mmol} / \mathrm{L})\end{array}$ & $\begin{array}{l}\text { Creatinine } \\
(\mu \mathrm{mol} / \mathrm{L})\end{array}$ \\
\hline $\mathrm{NC}$ & $64.0 \pm 3.0$ & $37.3 \pm 1.6$ & $26.7 \pm 1.9$ & $67.67 \pm 8.67$ & $8.3 \pm 0.6$ & $25.5 \pm 4.8$ \\
$\mathrm{CY}$ & $60.0 \pm 2.5$ & $36.2 \pm 2.1$ & $23.8 \pm 0.8^{*}$ & $66.00 \pm 14.48$ & $7.8 \pm 0.5$ & $30.3 \pm 4.2$ \\
CV5 & $62.8 \pm 2.0$ & $36.5 \pm 0.8$ & $26.3 \pm 1.5 \#$ & $53.83 \pm 8.04$ & $7.0 \pm 1.8$ & $25.2 \pm 7.0$ \\
CV10 & $60.2 \pm 3.0$ & $33.0 \pm 1.4^{*}$ & $27.2 \pm 1.8 \#$ & $53.83 \pm 9.02$ & $6.5 \pm 1.6$ & $25.2 \pm 5.0$ \\
CV15 & $63.8 \pm 2.3$ & $33.8 \pm 1.7^{*}$ & $30.0 \pm 1.3^{*} \#$ & $68.83 \pm 10.76$ & $5.9 \pm 1.1^{*}$ & $20.2 \pm 3.4 \#$ \\
\hline
\end{tabular}

Data presented as mean \pm SD $(n=6)$. $P<0.05$ is considered significant (one-way ANOVA followed by post-Hoc test Tukey HSD);

${ }^{*} \mathrm{p}<0.05$ compared to Group NC

$\# \mathrm{p}<0.05$ compared to Group $\mathrm{CY}$

ALT - alanine aminotransferase

\section{Body weight gain and relative weight of thymus and spleen}

The body weight gain, relative thymus and spleen weight results are shown in Table 4 . The groups that received VCO supplementation showed significant increments as compared to $\mathrm{CY}$ group. Although there were significant reduction in albumin levels and significant increase in globulin levels in the VCO groups, especially the ones receiving the higher dose, however the levels were all within the normal range including the $A / G$ ratio which did not go below the value of one. The level of Alanine Aminotransferase (ALT) as an indicator of liver cell injury and the levels of serum creatinine and blood urea as indicators of kidney function did not show any increase in all the VCO groups as compared to those of the normal control group.

Table 4. Weight gain and relative weight of thymus and spleen.

\begin{tabular}{llll}
\hline Group & $\begin{array}{l}\text { Weight gain in 6 weeks } \\
(\mathrm{g})\end{array}$ & Relative weight of thymus & $\begin{array}{l}\text { Relative weight of } \\
\text { spleen }\end{array}$ \\
\hline NC & $180.6 \pm 24.3$ & $0.135 \pm 0.014$ & $0.176 \pm 0.004$ \\
CY & $119.3 \pm 20.8^{*}$ & $0.085 \pm 0.014^{*}$ & $0.143 \pm 0.008$ \\
CV5 & $119.3 \pm 33.2^{*}$ & $0.089 \pm 0.037^{*}$ & $0.124 \pm 0.010$ \\
CV10 & $149.5 \pm 43.3$ & $0.092 \pm 0.015^{*}$ & $0.146 \pm 0.016$ \\
CV15 & $160.8 \pm 16.7$ & $0.105 \pm 0.018$ & $0.174 \pm 0.017$ \\
\hline
\end{tabular}

Data presented as mean \pm SD $(n=6) . P<0.05$ is considered significant (one-way ANOVA followed by post-Hoc test Tukey HSD);

* $\mathrm{p}<0.05$ compared to Group NC $\# \mathrm{p}<0.05$ compared to Group CY 


\section{DISCUSSION}

The current study revealed that VCO had protective effects against $\mathrm{CY}$-induced histological changes in lymphoid tissues of Wistar rats. This was as evidenced by the restoration of the histological architecture and lymphocytic cellularity of the thymus and spleen of the groups receiving both $\mathrm{CY}$ and VCO as compared to the group receiving only $\mathrm{CY}$ only. These histological findings were further supported by the significant increase in the TWCC, lymphocyte absolute counts and plasma globulin levels in the VCO groups as compared to group that received only $\mathrm{CY}$.

Cyclophosphamide, is a known cytotoxic drug used in this study due to its documented efficacy in yielding immunotoxicity in healthy animals as shown by previous studies. ${ }^{19,20}$ Clinical application of $\mathrm{CY}$ as an anticancer drug is often limited due to its harmful side effects. ${ }^{21} \mathrm{CY}$-induced immunotoxic reactions often manifested as immunosuppression. This immunosuppressive effect has long been regarded as problematic when treating patients with malignancies. ${ }^{22}$ Consequent to the immunocompromised state, the patients are susceptible to various infections which are associated with a higher rate of mortality. ${ }^{23}$

The depletion of lymphocytes population in the thymus of rats receiving only $\mathrm{CY}$ is consistent with previous observations that revealed decreased cellularity in the thymus of rats given $\mathrm{CY}$ orally at a dose of $10 \mathrm{mg} / \mathrm{kg} /$ day for 30 days; ${ }^{19}$ these changes are most probably attributed to the cytotoxic effects of $\mathrm{CY}$, predominantly on the lymphocytes and medullary epithelial cells, ${ }^{24}$ and to its immunotoxic effects which induces apoptosis, hypocellularity, and atrophy in the thymus. ${ }^{25}$

Reduction in lymphoid cellularity and alterations in the corticomedullary ratio, had been regarded as deleterious effect of xenobiotics on the thymus, and is considered as a highly sensitive indicator of immunotoxicant exposure. ${ }^{26}$ The reduction in the lymphoid cellularity in spleen of $\mathrm{CY}$ treated rats is in agreement with previous studies that observed depletion of $\mathrm{T}$ lymphocytes in mice treated with a single dose of $4 \mathrm{mg},{ }^{27}$ and $200 \mathrm{mg} / \mathrm{kg}$ of $\mathrm{CY},{ }^{28}$ and decreased cellularity in the spleen in rats treated daily with $10 \mathrm{mg} / \mathrm{kg} \mathrm{CY}$ for 30 days. ${ }^{19}$
Several studies have reported that naturally extracted remedies that possess high antioxidant property showed protective effects on $\mathrm{CY}$-induced myelosuppression and cytotoxicity in lymphoid tissues. ${ }^{29,30}$ As such, we assessed the protective effects of VCO against these effects; the VCO supplementation at $10 \mathrm{ml} / \mathrm{kg}$ and $15 \mathrm{ml} / \mathrm{kg}$ to the $\mathrm{CY}$ -treated rats were associated with improvement in the histologic architecture of both the thymus and spleen; this enhancement showed proportional favourable effects with the highest dose inducing the best response. The protective effects of the VCO against the $\mathrm{CY}$ induced injury could be closely linked to its contents of polyphenols as these had been identified as naturally occurring potent antioxidants. ${ }^{31}$ Another factor that may contribute to the medium -chain fatty acid composition of VCO that have been shown to have immunomodulatory effects. ${ }^{32}$ It has been demonstrated that lauric acid "the precursor of monolaurin" is an active compound in VCO, ${ }^{33}$ which has been shown to modulate immune cell proliferation and the potential to hamper tumor growth. ${ }^{34}$

The present study has demonstrated a significant increase in TWCC; absolute lymphocyte count and plasma globulin levels in the CY/VCO treated groups. As $\mathrm{CY}$ administration is known to induce lymphocyte depletion, ${ }^{35,36}$ the significant increment of TWCC and absolute lymphocytes count reflects restoration of leucopoiesis, specifically lymphopoiesis. Low levels of serum globulins following $\mathrm{CY}$ administration were also reported and may be indirectly linked to the immunological dysfunction. ${ }^{37}$ The elevation of globulin levels in VCO treated rats of this study may be associated with medium-chain fatty acid content of the oil that has been shown to enhance antibody production through IL-6 induction as demonstrated in an animal study, ${ }^{38}$ higher antioxidant activity, ${ }^{39}$ or it may be due to other mechanisms which have not yet been explored.

As for the body weight gain, relative thymus and spleen weights, although the significant gains in then VCO groups as compared to CY groups were not observed, there were increasing trends observed with increasing doses of VCO. The reduction in body weight gain and lymphoid organ weight following treatment with $\mathrm{CY}$ was primarily shown to be due to systemic inflammation, degradation of structural proteins and apoptosis-induced activity of $\mathrm{CY}$ and its metabolite known as acrolein; ${ }^{40}$ these 
pathophysiological processes were believed to result in reduced appetite and increased fatigability, thus, leading to muscle mass loss. It has been shown that consumption of VCO assists in increasing the energy level as well as preserving physical function and improve quality of life among the breast cancer patients, ${ }^{41}$ VCO improves fats and protein metabolism and has a positive effect on immune responses among HIV patients. ${ }^{42}$ The ability of VCO to mitigate the weight loss in rats treated with $\mathrm{CY}$ may also be attributable to the medium-chain fatty acids and polyphenols contents that hold immunomodulatory and antioxidant properties respectively. Additionally, the coconut oil supplies approximately 8 calories per $\mathrm{ml}$ which may also be beneficial in this context. ${ }^{17,41}$ It has been suggested that it is possible to prevent cancer by fatty acid supplementation and that VCO was shown to boost patients' energy and may have a place in supplementary treatment of cancer patients. ${ }^{43}$ VCO also promotes the immune system response, completely abolishes the predictable immune reactions to endotoxin and decreases the production of pro-inflammatory cytokines. ${ }^{44}$

Cyclophosphamide did not cause significant deleterious effects on the neutrophil count, RBC and platelet count, albumin, alanine aminotransferase, urea and creatinine levels to indicate myelo-suppression and/or systemic hepatorenal toxic effects in our experimental animals; suggesting that $C Y$ at $10 \mathrm{mg} / \mathrm{kg}$ orally for 4 weeks is sufficient to induce lymphocytic depletion and expected subsequent immunosuppression without causing apparent systemic toxicity. Our finding concurs with previous studies that reported $\mathrm{CY}$ administration at low to moderate dosages resulted in depletion of lymphocytes prior to the myelosuppression stage. ${ }^{35,45}$ Further immunohistochemical studies using CD3 and CD20 polyclonal antibodies for detection of $\mathrm{T}$ and $\mathrm{B}$ lymphocytes populations and to evaluate the immunoprotective effect of VCO against $\mathrm{CY}$-induced histological changes in lymphoid tissues are in progress.

\section{CONCLUSION}

In conclusion, this study demonstrated the immunoprotective effects of VCO against cytotoxicity induced by $\mathrm{CY}$ in lymphoid tissues as observed by significant improvement in the microscopic architecture and cellularity of thymus and spleen, the peripheral TWCC and lymphocyte counts and plasma globulin level in a dosedependent manner. These findings should encourage the conduction of further experiments and later clinical research on the immunoprotective effect of VCO intake in cancer subjects treated with cytotoxic drugs.

\section{ACKNOWLEDGEMENTS}

This research was supported by the International Islamic University Malaysia (EDW B 14-218-1103) and by RIGS Project No.RIGS16-298-0462. We would like to express sincere appreciation to all technical staffs of the Department of Basic Medical Sciences, KOM, IIUM for their great assistance during the course of this research.

\section{REFERENCES}

1. Alizadeh A, Alarmonier N. Chemotherapeutic targeting of cancer- induced immunosuppressive cells. Cancer Res 2014; 74(10): 2663-8.

2. Zheng PP, LiMD J, MKros J. Breakthroughs in moderncancer therapy and elusive cardiotoxicity: Critical research-practice gaps, challenges, and insights. Med Res Rev 2018; 38: 325-76.

3. Ladas EJ, Jacobson JS, Kennedy DD, et al. Antioxidants and cancer therapy: a systematic review. J Clin Oncol 2004; 22(3): 517-28.

4. Singh N, Tailang M, Mehta S. A Review on Herbal Plants as Immunomodulators. Int J Pharm Sci Res 2016; 7(9): 3602-10.

5. Song $\mathrm{YH}$, Sun $\mathrm{H}$, Zhang $\mathrm{AH}$, et al. Plant derived natural products as leads to anti-cancer drugs. J Med Plant Herb Ther Res 2014; 2: 6-15.

6. Salian V, Shetty P. Coconut Oil and Virgin Coconut Oil: An Insight into its Oral and Overall Health Benefits. Journal Clinical and Diagnostic Research. 2018; 12(1): ZE01-ZE03.

7. Zakaria ZA, Somchit MN, Mat Jais AM, et al. In vivo antinociceptive and anti-inflammatory activities of dried and fermented processed virgin coconut oil. Med Prin Prac 2011; 20 (3): 231-6.

8. Kappally S, Shirwaikar A, Shirwaikar A. Coconut oil - a review of potential applications. Hygeia J D Med 2015; 7 (2) 34-41.

9. Evangelista, M. T. P., Abad-Casintahan, F., \& Lopez-Villafuerte, L. (2014). The effect of topical virgin coconut oil on SCORAD index, 
transepidermal water loss, and skin capacitance in mild to moderate pediatric atopic dermatitis: a randomized, double-blind, clinical trial. International journal of dermatology, 53(1), 100-108.

10. Varma SR, Sivaprakasam TO, Arumugam L, Dilip N, Raghuraman M, Pavan KB, Rafiq M, Paramesh R. In vitro anti-inflammatory and skin protective properties of Virgin coconut oil. Journal of Traditional and Complementary Medicine. 2017; https://doi.org/10.1016/ j.jtcme.2017.06.012

11. Satheesh N. Review on Production and Potential Applications of Virgin Coconut Oil. Ann Food Sci Technol 2015; 16(1): 115-26.

12. Chinwong S, Chinwong D, MangklabruksA. Daily Consumption of Virgin Coconut Oil Increases High-Density Lipoprotein Cholesterol Levels in Healthy Volunteers: A Randomized Crossover Trial. Hindawi Evidence-Based Complementary and Alternative Medicine. 2017; Article ID 7251562: https:// doi.org/10.1155/2017/7251562

13. Khaw K-T, Sharp SJ, Finikarides L. Randomised trial of coconut oil, olive oil or butter on blood lipids and other cardiovascular risk factors in healthy men and women. BMJ Open 2018;8: e020167. doi:10.1136/bmjopen-2017-020167

14. Fife B, Kabara J. The coconut oil miracle. $4^{\text {th }}$ Edition, New York: Avery, U.S.A., ISBN 1583332049 (ISBN13: 9781583332047 2004; pp. 17-20.

15. Marina AM, Man YB, Nazimah SA, et al. Antioxidant capacity and phenolic acids of virgin coconut oil. Int J Food Sci Nutr 2009; 60 (2): 114-23.

16. Zentek J, Buchheit-Renko S, Ferrara F, et al. Nutritional and physiological role of mediumchain triglycerides and medium-chain fatty acids in piglets. Anim Health Res Rev 2015; 12 (01): 83-93.

17. Fernando WM, Martins IJ, Goozee KG, et al. The role of dietary coconut for the prevention and treatment of Alzheimer's disease: potential mechanisms of action. British J Nut 2015; 114 (1): 1-14.

18. Mansor TS, Che Man YB, Shuhaimi M, et al. Physicochemical properties of virgin coconut oil extracted from different processing methods. Int Food Res J 2012; 19 (3): 837-45.

19. Hou FX, Yang HF, Yu T, et al. The immunosuppressive effects of $10 \mathrm{mg} / \mathrm{kg}$
Cyclophosphamide in Wistar rats. Environ

Toxicol Pharmacol 2007; 24(1): 30-6.

20. Nair SS, Manalil JJ, Ramavarma SK, et al. Virgin coconut oil supplementation ameliorates CYinduced systemic toxicity in mice. Human Exp Toxicol 2015; 35(2): 205-12.

21. Sheweita SA, El-Hosseiny LS, Nashashibi MA. Protective Effects of Essential Oils as Natural Antioxidants against Hepatotoxicity Induced by Cyclophosphamide in Mice. PLOS ONE. 2016; DOI:10.1371/journal.pone.0165667

22. Morrison VA. Immunosuppression associated with novel chemotherapy agents and monoclonal antibodies. Clin Inf Dis 2014; 59(5): 360-4.

23. Descotes J. Immunotoxicity Evaluation: A View of the Future. Encyclopedia of Immunotoxicology, Springer Berlin Heidelberg, Berlin, German 2015; pp. 464-7.

24. Fletcher AL, Lowen TE, Sakkal S, et al. Ablation and regeneration of tolerance-inducing medullary thymic epithelial cells after cyclosporine, Cyclophosphamide, and dexamethasone treatment. J Immun 2009; 183 (2): 823-31.

25. Yan F, Mo Z, Liu J, Ye S, Zeng X, Chen D. Thymic function in the regulation of $T$ cells, and molecular mechanisms underlying the modulation of cytokines and stress signalling. Molecular medicine reports. 2017; 16: 71757184

26. Menke A, Wolterbeek A, Snel C, et al. Potentially increased sensitivity of pregnant and lactating female rats to immunotoxic agents. Toxicol Pathol 2012; 40(2): 255-60.

27. Salem Ml, Díaz-Montero CM, Al-Khami AA, et al. Recovery from Cyclophosphamide-induced lymphopenia results in expansion of immature dendritic cells which can mediate enhanced prime-boost vaccination antitumor responses in vivo when stimulated with the TLR3 agonist poly (I: C). J Immunol 2009; 182(4): 2030-40.

28. Radojcic V, Bezak Kb, Skarica M, et al. Cyclophosphamide resets dendritic cell homeostasis and enhances antitumor immunity through effects that extend beyond regulatory T cell elimination. Cancer Immunol Immunoth 2010; 59(1): 137-48.

29. Im SA, Kim KH, Kim HS, et al. Processed Aloe vera Gel Ameliorates CyclophosphamideInduced Immunotoxicity. Int J Mol Sci 2014; 15 (11): 19342-54. 
30. Yu Q, Nie SP, Wang JQ, et al.

Chemoprotective effects of Ganoderma atrum polysaccharide in Cyclophosphamide-induced mice. Int J Bio Macromol 2014; 64: 395-401.

31. Arunima S, Rajamohan T. Effect of virgin coconut oil enriched diet on the antioxidant status and paraoxonase 1 activity in ameliorating the oxidative stress in rats-a comparative study. Food Fun 2013; 4(9): 1402 $-9$.

32. Narayanankutty A, Mukesh RK, Ayoob SK, et al. Virgin coconut oil maintains redox status and improves glycemic conditions in high fructose fed rats. J Food Sci Technol 2016; 53 (1): 895-901.

33. Pereira CC, Da Silva MA, Langone MA. (2004): Enzymatic synthesis of monolaurin. Appl Biochem Biotechnol 113-116: 433-445.

34. Lappano R, Sebastiani A, Cirillo F, Rigiracciolo $D C$. The lauric acid-activated signaling prompts apoptosis in cancer cells. Cell Death Discovery. 2017; 3, 17063; doi:10.1038/ cddiscovery.2017.6

35. Merwid-Ląd A, Trocha M, ChlebdaSieragowska E, et al. The Effects of Morin, a Naturally Occurring Flavonoid, on Cyclophosphamide-Induced Toxicity in Rats. Adv Clin Exp Med 2011; 20(6): 683-90.

36. Zwang NA, Turka LA. Homeostatic expansion as a barrier to lymphocyte depletion strategies. Curr Opin Organ Tran 2014; 19 (4): 357-62.

37. Wojcik R. Reactivity of the immunological system of rats stimulated with Biolex-Beta HP after Cyclophosphamide immunosuppression. Centr Eur j immunol 2014; 39 (1): 51-60.

38. Kono H, Fujii H, Asakawa M, et al. Mediumchain triglycerides enhance secretory IgA expression in rat intestine after administration of endotoxin. Am J Physiol Gastrointest Liver Physiol 2004; 286(6): 1081 9.

39. Nurul-Iman BS, Kamisah Y, Jaarin K, Qodriyah MS. Virgin Coconut Oil Prevents Blood Pressure Elevation and Improves Endothelial Functions in Rats Fed with Repeatedly Heated Palm Oil. Evidence-Based Complementary and Alternative Medicine. 2013, Article ID 629329, http://dx.doi.org/10.1155/2013/629329

40. Korkmaz A, Topal T, Oter S.

Pathophysiological aspects of
Cyclophosphamide and ifosfamide induced hemorrhagic cystitis; implication of reactive oxygen and nitrogen species as well as PARP activation. Cell Biol Toxically 2007; 23(5): 303 $-12$.

41. Law KS, Azman N, Omar EA, et al. The effects of virgin coconut oil (VCO) as supplementation on quality of life (QOL) among breast cancer patients. Lipids Health Dis 2014; 13(1): 1-7.

42. Soerjodibroto W: Research Report on the Effects of Virgin Coconut Oil on Immune Responses among HIV Positive Patients in Dharmais Hospital, Jakarta. 2006.

43. Mohammad, A., Faruqi, F. B., \& Mustafa, J. (2009). Cancer: possible prevention and chemotherapy by fatty materials:( a review). Archives of Applied Science Research, 1(2), 178-199.

44. Wojdasiewicz P, Poniatowski LA, Szukiewicz D. The Role of Inflammatory and AntiInflammatory Cytokines in the Pathogenesis of Osteoarthritis. Mediators of Inflammation. 2014, Article ID 561459, http:// dx.doi.org/10.1155/2014/561459

45. Gupta A, Gautam MK, Singh RK, et al. Immunomodulatory effect of Moringa oleifera Lam. extract on $\mathrm{CY}$ induced toxicity in mice. Indian J Exp Biol 2010; 48(11): 1157-60. 